\title{
Agrometeorological models for predicting seedlings development of two native forest
} species

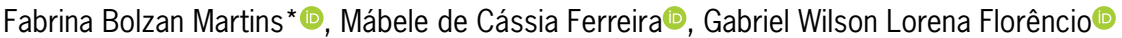

Universidade Federal de Itajubá/Instituto de Recursos Naturais, C.P. 50 - 37500-903 - Itajubá, MG - Brasil. *Corresponding author <fabrina@unifei.edu.br>

Edited by: Jason N. James

Received July 01, 2020

Accepted March 17, 2021

\begin{abstract}
Models of development are tools that connect the effects of development on the environment, allowing their applications in several studies. Nevertheless, studies are scarce on models of development for native forest species in Brazil. This study aimed to predict the development of two native forest species - Citharexylum myrianthum Cham. and Bixa orellana L. with two agrometeorological models, being one linear (Phyllochron) and another nonlinear (Wang and Engel, 1998). Both models predict the cumulative leaf number (CLN) on a daily basis, which generates the seedling phase duration (SPD) when integrated to time. Data were used from two years of experiments conducted during 2015 and 2016 growing seasons and 12 sowing dates in Itajubá, Minas Gerais State, Brazil. These species $\times$ sowing dates $\times$ years experiments provided a rich dataset for calibrating and evaluating both models. Although both models used in the study allowed predicting the dynamics of leaf development, CLN, and SPD in two native forest species, the Wang and Engel model provided a more accurate prediction of CLN and SPD for $C$. myrianthum species, with an overall root mean square error (RMSE) of 1.82 leaves (CLN) and 5.9 days (SPD). For $B$. orellana, the Phyllochron model was slightly better, with an overall RMSE of 1.48 leaves (CLN) and seven days (SDP).
\end{abstract}

Keywords: Bixa orellana L., Citharexylum myrianthum Cham, air temperature, leaf appearance, phenology

\section{Introduction}

The forest-based sector plays an important role in the Brazilian economy, accounting for $6.9 \%$ of Gross Domestic Product (GDP), which represented US\$ 12.5 billion in 2018 (IBÁ, 2019). In the forestry production chain, producing high quality seedlings remains a priority, due to the strong relationship with tree planting success and high forest yield (Freitas et al., 2017; Willians and Dumroese, 2014). Seedling quality assessment has evolved to include dynamics of leaf development as a definition of seedling performance. In these sense, models of development are an important tool to predict the dynamics of leaf development, including seedling phase duration (SPD), and to provide quantitative information to support decisions of nursery management at field scale (Ferreira et al., 2019b; Freitas et al., 2017; Martins et al., 2014). Models of development allow obtaining the cumulative leaf number (CLN) on the main stem and SPD through the relationship between the leaf appearance rate (LAR) and air temperature function $(\mathfrak{f}(t)$ ) (Ferreira et al., 2019b; Martins and Streck, 2007). Air temperature is the main abiotic factor in forest development (Freitas et al., 2017; Rawal et al., 2015), including native forest species (Ferreira et al., 2019a, b; Monteiro et al., 2014). The $f(t)$ on forest species has two approaches used in models of development: thermal time approach and beta function (Martins et al., 2014; Ulhmann et al., 2017).

In Brazil, models of development are mostly used in agricultural crops (Erpen et al., 2013; Langner et al., 2018; Streck et al., 2007, 2008, 2011, 2013) with little use in forest crops (Ferreira et al., 2019b; Martins and Streck, 2007; Monteiro et al., 2014). In addition, most forest commercial nurseries in Brazil do not use models of development to predict the CLN and SDP, despite their potential (Ferreira et al., 2019b; Florêncio et al., 2019; Martins et al., 2014). Since few studies of this nature have been conducted on native forest species, besides the lack of a development model for C. myrianthum Cham. and Bixa orellana L., this study calibrated and evaluated two agrometeorological models of seedlings development with two $f(t)$ approaches to predict CLN and SDP for both species, which are of major importance to Brazilian flora due to their value in the agricultural, pharmaceutical, and cosmetic sectors, in addition to their contribution to forest restoration programs (Ferreira et al., 2019a).

\section{Materials and Methods}

\section{Field experiment data}

The data used in this study are from two years of experiments conducted in the field study site, Itajubá, Minas Gerais State, Brazil $\left(22^{\circ} 24^{\prime} 46.43^{\prime \prime}\right.$ S $45^{\circ} 26^{\prime} 48.94^{\prime \prime}$ $\mathrm{W}$, altitude of $1.050 \mathrm{~m}$ ), during the 2015 and 2016 growing seasons. The site has a subtropical subhumid climate according to Köppen-Geiger climate classification (Freitas et al., 2017). The experiments were carried out in a completely randomized design with two native forest species, C. myrianthum Cham. and B. orellana L., cultivated in $8.0 \mathrm{~L}$ white polyethylene pots in 12 sowing dates (SD) (Table 1) performed at 30-day intervals and five 
Table 1 - Sowing dates (SD), emergence dates and end of seedling phase dates for two native forest species (Citharexylum myrianthum and Bixa orellana) during the period in which the experiment was carried out in Itajubá, Minas Gerais, Brazil.

\begin{tabular}{|c|c|c|c|c|}
\hline \multirow{2}{*}{$\begin{array}{l}\text { Sowing date } \\
\text { Day/month/year }\end{array}$} & \multicolumn{2}{|c|}{ Citharexylum myrianthum } & \multicolumn{2}{|c|}{ Bixa orellana } \\
\hline & $\begin{array}{l}\text { Emergence date } \\
(\mathrm{VE})^{1}\end{array}$ & $\begin{array}{c}\text { End of seedling } \\
\text { phase }^{2}\end{array}$ & $\begin{array}{l}\text { Emergence date } \\
(\text { VE) })^{1}\end{array}$ & $\begin{array}{c}\text { End of seedling } \\
\text { phase }^{2}\end{array}$ \\
\hline SD1, 12/05/2015 & $10 / 06 / 2015$ & $18 / 11 / 2015$ & $12 / 06 / 2015$ & 06/01/2016 \\
\hline SD2, 12/06/2015 & 15/07/2015 & 09/12/2015 & 10/07/2015 & 22/01/2016 \\
\hline SD3, 10/07/2015 & 05/08/2015 & 23/12/2015 & 28/07/2015 & 27/01/2016 \\
\hline SD4, 11/08/2015 & 02/09/2015 & $30 / 12 / 2015$ & 26/08/2015 & 11//022016 \\
\hline SD5, 10/09/2015 & $05 / 10 / 2015$ & $27 / 01 / 2016$ & $30 / 09 / 2015$ & $29 / 02 / 2016$ \\
\hline SD6, 09/10/2015 & 04/11/2015 & $01 / 03 / 2016$ & $19 / 10 / 2015$ & 07/04/2016 \\
\hline SD7, 13/11/2015 & 08/12/2015 & 07/04/2016 & $27 / 11 / 2015$ & $12 / 05 / 2016$ \\
\hline SD8, 11/12/2015 & 04/01/2016 & $12 / 05 / 2016$ & $28 / 12 / 2015$ & $19 / 05 / 2016$ \\
\hline SD9, 12/01/2015 & 07/02/2016 & $19 / 05 / 2016$ & $27 / 01 / 2016$ & $11 / 08 / 2016$ \\
\hline SD10, 11/02/2016 & 04/03/2016 & $21 / 07 / 2016$ & $19 / 02 / 2016$ & $25 / 08 / 2016$ \\
\hline SD11, 11/03/2016 & $31 / 03 / 2016$ & $11 / 08 / 2016$ & 24/03/2016 & $15 / 09 / 2016$ \\
\hline SD12, 12/04/2016 & 05/05/2016 & $15 / 09 / 2016$ & 03/05/2016 & 10/06/2016 \\
\hline
\end{tabular}

${ }^{1}$ Emergence day was assumed when $50 \%$ of the seedlings were visible at the soil surface; ${ }^{2}$ End of seedling phase was assumed when both native forest species reached 20 accumulated leaves on the main stem that is considered the most suitable plateau to seedling phase (Ferreira et al., 2019a).

replications (replication $=$ pot), or 10 pots per SD. The wide range of SD was selected to have plants developing under different meteorological conditions, especially temperature (Figures $1 \mathrm{~A}$ and 1B), important for model calibration and evaluation (Ferreira et al., 2019b; Martins et al., 2014). The SD were divided into two groups: the first (SD1 to SD5) was used to calibrate the model coefficients (see details in item "calibrating the model coefficients") and the second (SD6 to SD12) was used to evaluate the models performance (see details in item "evaluating models").

The pots were filled with moderate type A horizon subsoil of a Rhodic Hapludox Oxisol (Santos et al., 2013), collected in the municipality of Itajubá, Minas Gerais State. The chemical characteristics included $2.50 \mathrm{dag} \mathrm{kg}^{-1}$ of OM (Walkley-Black), $0.6 \mathrm{mg} \mathrm{dm}^{-3}$ of $\mathrm{P}$, and $5.0 \mathrm{mg} \mathrm{dm}^{-3}$ of $\mathrm{K}$, obtained by the Mehlich extractor 1 . About 90 days before SD, fertility and acidity were corrected according to the Commission for Soil Fertility in the State of Minas Gerais (CFSEMG, 1999) by applying $8.40 \mathrm{~g}$ of simplesuperphosphate (18\%), $0.256 \mathrm{~g}$ of potassium chloride $(60 \%), 0.35 \mathrm{~g}$ of ammonium sulfate $(20 \%), 6.45 \mathrm{~g}$ of magnesium carbonate, and $12.20 \mathrm{~g}$ of calcium carbonate. At approximately 90-120 days after SD, cover fertilization was performed by applying $0.575 \mathrm{~g}$ potassium chloride and $0.575 \mathrm{~g}$ ammonium sulfate in each pot.

Seeds of the native forest species $C$. myrianthum and $B$. orellana were obtained in two dispersion periods (2015/2016) from plantations in the municipalities of Piranguinho, São José do Alegre, and Pedralva, all located in the southern region of Minas Gerais State, Brazil. Seeds viability during the experiment was conserved according to recommendations of Lorenzi (2014) and Embrapa (2001).

\section{Seedling development models}

In this study, two models of development were used: Phyllochron (Phyl) and Wang Engel (WE). Both models simulate CLN on a daily basis from emergence (VE) until end of seedling phase (Table 1) to obtain SPD. The end of seedling phase occurs when plants reach 20 leaves on the main stem, considered the most suitable plateau to define the end of seedling phase in $C$. myrianthum and B. orellana (Ferreira et al., 2019a).

Simulation of CLN requires the daily calculation of LAR. In the Phyl model, LAR was adapted from Martins et al. 2014 and Florencio et al. 2019, obtained by:

$L A R=a . T T d$

where: $L A R=$ daily leaf appearance rate $\left(\right.$ leaves $\left.\mathrm{d}^{-1}\right)$; $a=$ slope of linear regression between $L A R$ and TTd (leaves per ${ }^{\circ} \mathrm{C}$ day), specific coefficient for each native forest species (see details in item "calibrating the model coefficients"); $T T d=$ daily thermal time $\left({ }^{\circ} \mathrm{C}\right.$ day $)$ calculated by (Florencio et al., 2019; Streck et al., 2011):

$$
T T d= \begin{cases}0 & \text { when } T<T b \text { or } T>T B \\ T-T b & \text { when } T b \leq T \leq T o p t \\ \frac{(T o p t-T b) \cdot(T B-T)}{(T B-T o p t)} & \text { when } T o p t<T \leq T B\end{cases}
$$

where: $T=$ daily mean air temperature from an automatic weather station in the field experimental site; $T b$, Topt and $T B=$ cardinal temperatures (minimum, optimum, and maximum) for LAR, respectively. Cardinal temperatures for $C$. myrianthum are $\mathrm{Tb}=11.4^{\circ} \mathrm{C}$, Topt $=18.1{ }^{\circ} \mathrm{C}$, TB $=36.6{ }^{\circ} \mathrm{C}$ and for B. orellana are $\mathrm{Tb}=12{ }^{\circ} \mathrm{C}$, Topt $=$ $18.4{ }^{\circ} \mathrm{C}, T B=46.4{ }^{\circ} \mathrm{C}$ (Ferreira et al., 2019a). Cardinal temperatures and schematic representation of the TTd method are shown in Figure 2A.

In the WE model, LAR was calculated by combining nonlinear temperature function and age effects on LAR in a multiplicative fashion, given by (Ferreira et al., 2019b):

$$
L A R=L A R_{\max } \cdot f(t)
$$



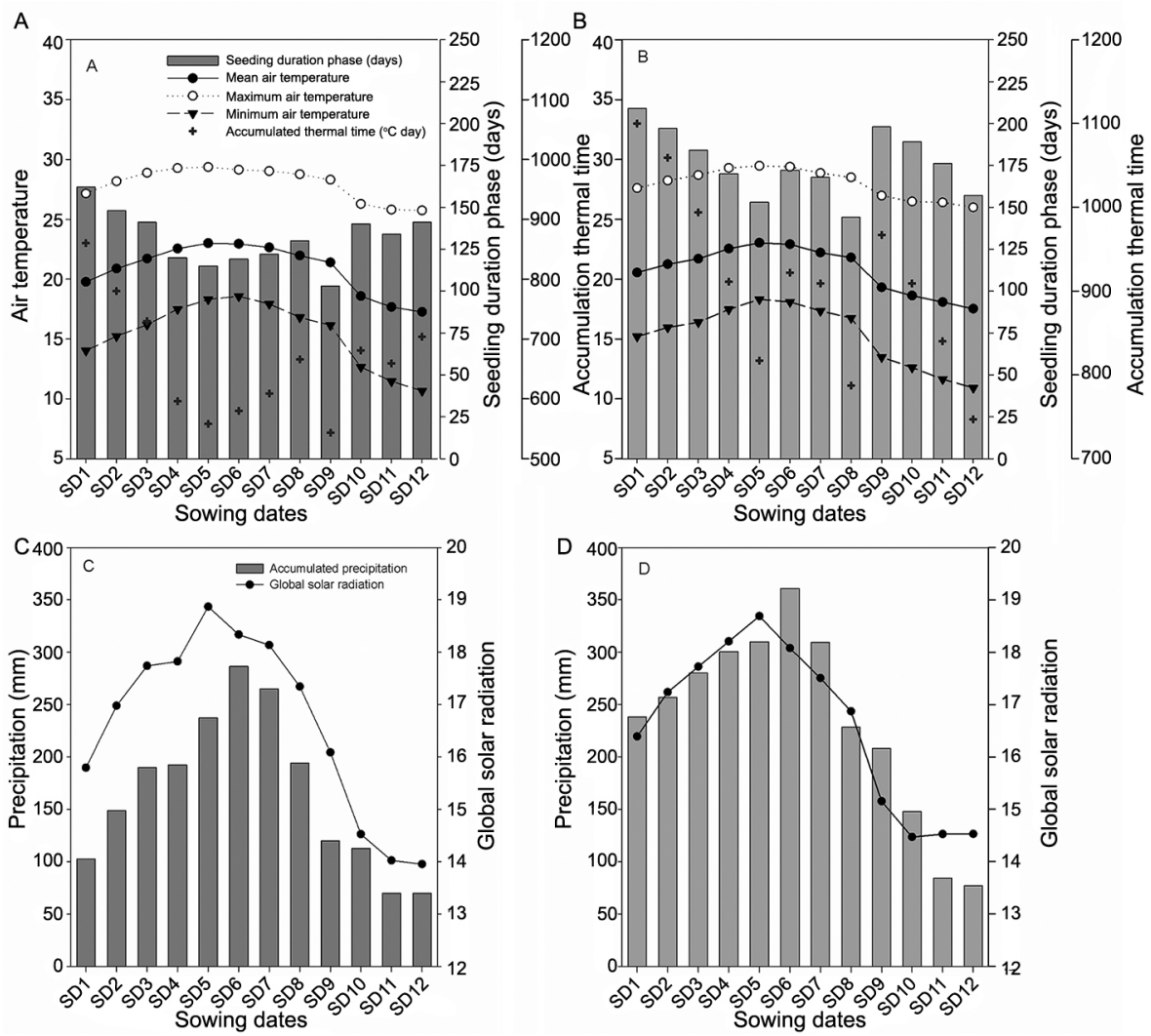

Figure 1 - Sowing dates (SD) variation of air temperature $\left({ }^{\circ} \mathrm{C}\right.$, panels $\mathrm{A}$ and $\left.\mathrm{B}\right)$ - minimum, mean and maximum, seedling phase duration (days, panels $A$ and $B$ ), accumulated thermal time $\left({ }^{\circ} \mathrm{C}\right.$ day, panels $A$ and $\left.B\right)$, accumulated precipitation ( $\mathrm{mm}$, panels $\mathrm{C}$ and $\left.\mathrm{D}\right)$ and average global solar radiation ( $M j ~ m^{-2} \mathrm{~d}^{-1}$, panels $C$ and $D$ ) for two native forest species: (A and $C$ ) Citharexylum myrianthum and (B and D) Bixa orellana during field experiments carried out in Itajubá, Minas Gerais, Brazil.

where: $L A R=$ daily leaf appearance rate $\left(\right.$ leaves $\left.\mathrm{d}^{-1}\right)$; $L A R_{\max }=$ species specific maximum daily leaf appearance rate (leaves $\mathrm{d}^{-}$) (see details in item "calibrating the model coefficients"); $f(t)=$ beta temperature response function (from 0 to 1) given by (Florencio et al., 2019; Uhlmann et al., 2017):

$$
f(t)= \begin{cases}0 & \text { when } T<T b \text { or } T>T B \\ \frac{\left[2(T-T b)^{\alpha}(T o p t-T b)^{\alpha}-(T-T b)^{2 \alpha}\right]}{(T o p t-T b)^{2 \alpha}} & \text { when } T b \leq T \leq T B\end{cases}
$$

$\alpha=(\ln 2) /(\ln [(T B-T b) /(T o p t-T b)])$

where: $T, T b, T o p t$ and $T B$ are given as previously mentioned; $\alpha=$ coefficient of $f(t)$. The beta temperature function is shown in Figure 2B.

The CLN is calculated by accumulating daily LAR values, that is, $\mathrm{CLN}=\Sigma \mathrm{LAR}$, using the Phyl and WE models, from VE until the seedling phase end (Ferreira et al., 2019b; Martins et al., 2014). The SPD is defined as the duration in days for the plants to reach 20 leaves on the main stem, ranging from VE (day 1 ) to CLN $=20$ (day n) (Ferreira et al., 2019a).

\section{Calibrating the model coefficients}

Coefficients 'a' (Phyl model) and LAR ${ }_{\max }$ (WE model) were calibrated using data of SD1 to SD5. Coefficients of the Phyl model were calibrated by the linear regression between CLN and accumulated TTd applied for each SD and native forest species (Martins et al., 2014). The ' $a$ ' coefficient was obtained by the arithmetic mean of these regressions (Ferreira et al., 2019b; Martins et al., 2014; Streck et al., 2011). LAR max $_{\text {was }}$ wastimated through the nonlinear regressions between CLN in relation to the accumulated values of $f(T)$ for each SD and native forest species. The $\mathrm{LAR}_{\max }$ value was considered as the value obtained from the regression with the lowest value of the mean square error (MSE) (Ferreira et al., 2019b; Martins et al., 2014). The nonlinear estimation procedure applied the Gauss-Newton variant, using the ordinary least squares method.

\section{Models evaluation}

The model was evaluated using CLN data predicted and observed from SD6 to SD12, independent data sets. The statistical data used to evaluate the model performance 

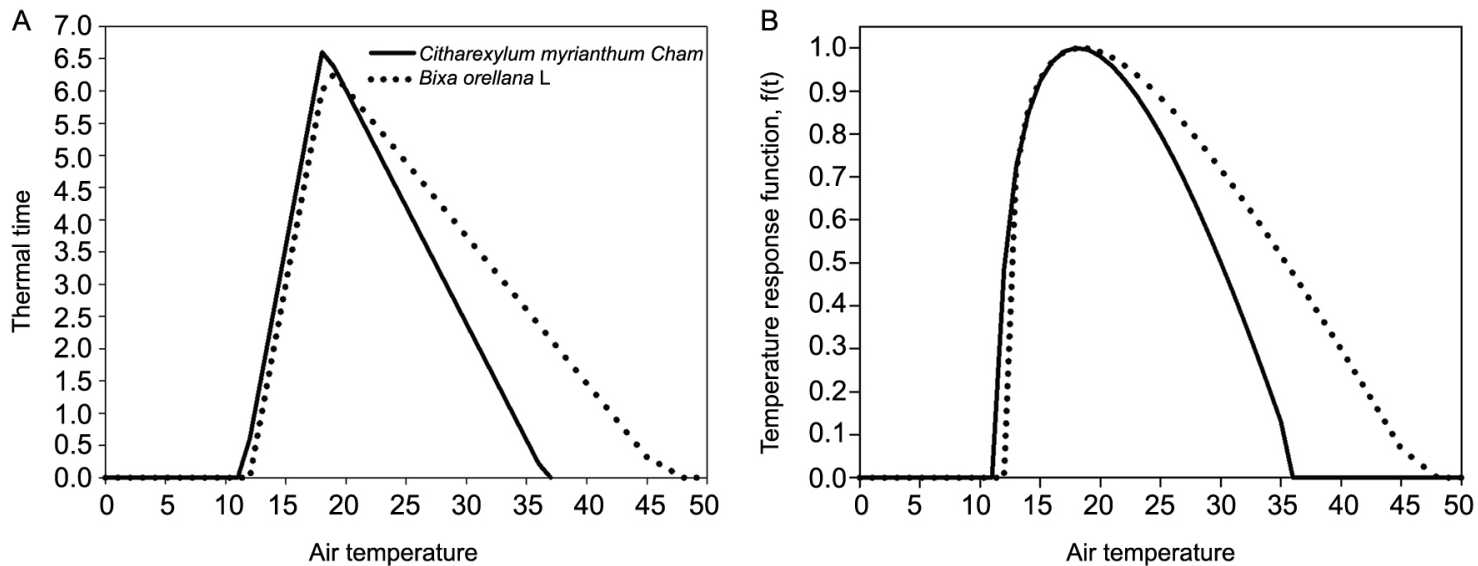

Figure 2 - The temperature response functions used in the Phyllochron model (A) given by thermal time approach, and Wang and Engel model (B) given by the beta temperature response function, to predict the leaf number with cardinal temperatures for Citharexylum myrianthum (Tb $=$ $11.4{ }^{\circ} \mathrm{C}$, Topt $=18.1{ }^{\circ} \mathrm{C}$ and $\mathrm{TB}=36.6^{\circ} \mathrm{C}$ ) and Bixa orellana $\left(\mathrm{Tb}=12{ }^{\circ} \mathrm{C}\right.$, Topt $=18.4{ }^{\circ} \mathrm{C}$ and $\mathrm{TB}=46.4^{\circ} \mathrm{C}$ ).

were: root mean square error (RMSE), mean bias error (BIAS), Willmott index of agreement (d), performance index (c-index) (Ferreira et al., 2019b; Monteiro and Martins, 2019):

$$
\begin{aligned}
& R M S E=\sqrt{\frac{\sum_{i=1}^{n d}\left(E_{i}-O_{i}\right)^{2}}{n d}} \\
& B I A S=\frac{\sum_{i=1}^{n d} E_{i}-\sum_{i=1}^{n d} O_{i}}{\sum_{i=1}^{n d} O_{i}} \\
& d=1-\left(\frac{\sum_{i=1}^{n d}\left(E_{i}-O_{i}\right)^{2}}{\sum_{i=1}^{n d}\left(\left|E_{i}-\bar{O}\right|+\left|O_{i}-\bar{O}\right|\right)^{2}}\right)
\end{aligned}
$$

Criteria of performance interpretation to c-index (c): > 0.85: excellent; 0.76 to 0.85 : very good; 0.66 to 0.75: good; 0.61 to 0.65 : reasonable; 0.51 to 0.60 : poor; 0.41 to 0.50 : very poor, and $\leq 0.40$ : extremely poor (Monteiro and Martins, 2019):

$$
c-\text { index }=\left(\frac{\sum\left(E_{i}-\bar{E}\right)\left(O_{i}-\bar{O}\right)}{\sqrt{\sum\left(E_{i}-\bar{E}\right)^{2} \sum\left(O_{i}-\bar{O}\right)^{2}}}\right) \cdot d
$$

where: $E_{i}=$ predicted values by the Phyl and WE models; $\frac{i}{E}=$ average of the predicted values by the Phyl and WE models; $O_{i}=$ observed values; $\bar{O}=$ average of the observed values; nd $=$ number of data.

Additionally, variance homogeneity between predicted and observed CLN values for both models was tested using the Bartlett test $\left(\mathrm{H}_{0}=\right.$ homogeneous variances $-p \geq 0.05$ versus $\mathrm{H}_{1}=$ heterogeneous variances $-p<0.05)$ (Snedecor and Cochran, 1989):

$$
B=\frac{(\Sigma v i) \ln \left(\frac{\Sigma v i S i^{2}}{\Sigma v i}\right)-\Sigma v i \ln S i^{2}}{1+\left\{\Sigma\left(\frac{1}{v i}\right)-1\right\} /\{3(K-1)\}}
$$

where: $B=$ Bartlett test value; $v i=\mathrm{n}-1$ and $\mathrm{n}=$ number of data; $S i^{2}=$ variance between observed CLN and predicted CLN (for each model and species); $K=2$ refers to observed and estimated pooled data.

The Bartlett test can also be used to test data normality (Monteiro and Martins, 2019) and it was used in this study at the same probability level. In addition, the observed mean values of CLN were compared using the paired t-test, with the mean values predicted. The paired t-test showed that $\mathrm{H}_{0}=$ mean of observed CLN was equal to the mean of predicted CLN (for each model and species) $(p \geq 0.05)$ versus $\mathrm{H}_{1}=$ mean of observed CLN is unequal to mean of predicted $(p<0.05)$, by Snedecor and Cochran (1989):

$t=\frac{\bar{O} 1-\bar{E} 1}{\frac{S i^{2}}{\sqrt{n}}}$

where: $t=$ paired t-test value; $\bar{O}_{1}=$ average of the observed values; $\bar{E}_{1}=$ average of the predicted values; $\mathrm{Si}^{2}=$ variance between observed CLN and predicted CLN (for each model and species); $n=$ number of data.

Moreover, SPD obtained by the Phyl and WE models were compared by the paired t-test at the same probability level considering each native forest species between the SD.

\section{Results}

Weather conditions varied greatly during the field experiments (Figures 1A-D). In general, air temperature ranged from $2.3^{\circ} \mathrm{C}$ (minimum absolute value) from SD9 to $\mathrm{SD} 12$, to $35.7^{\circ} \mathrm{C}$ (maximum absolute value) observed from $\mathrm{SD} 1$ to SD6. Global solar radiation ranged from $2.6 \mathrm{Mj} \mathrm{m}^{-2}$ $\mathrm{d}^{-1}$ (minimum absolute value) to $30.0 \mathrm{Mj} \mathrm{m}^{-2} \mathrm{~d}^{-1}$ (maximum absolute value). The municipality of Itajubá has a typical monsoon climate, with two well-defined seasons: dry winters and humid summers (Freitas et al., 2017), which contributed to the highest precipitation accumulated 
during SD6 and the lowest precipitation from SD11 to SD12. The distinct meteorological conditions, mainly air temperatures during different SDs, provide a rich dataset to calibrate and evaluate the development model applied to the seedling phase in native forest species.

Calibration coefficients (Phyl and WE models) vary between both forest species and coefficients are significant by the t-test $(p \leq 0.05)$. Besides, variation of these coefficients between both forest species during the seedling phase showed that the earlier species (shortest developmental cycle) was the lower ' $a$ ' coefficient and accumulated TTd, and the higher $\mathrm{LAR}_{\max }$. In the Phyl model, ' $a$ ' values are 0.0300 leaves per ${ }^{\circ} \mathrm{C}$ day for $C$. myrianthum and 0.0203 leaves per ${ }^{\circ} \mathrm{C}$ day for $B$. orellana. In the Phyl model, the biological meaning of 'a' coefficient may be evaluated by taking the inverse of ' $a$ ' coefficient, that is, $1 / 0.030\left(33.33{ }^{\circ} \mathrm{C}\right.$ day per leaf) or $1 / 0.0203$ (49.26 ${ }^{\circ} \mathrm{C}$ day per leaf), and represents the thermal requirements necessary to emit a leaf on the main stem (Martins and Streck, 2007; Erpen et al., 2013; Freitas et al., 2017; Ferreira et al., 2019b). In this approach, the thermal time accumulation for reaching the end of the seedling phase (CLN $=20$ leaves) varied from approximately $667{ }^{\circ} \mathrm{C}$ day (C. myrianthum) to $925^{\circ} \mathrm{C}$ day (B. orellana). For $C$. myrianthum, this thermal time accumulation was realistic under field conditions mainly in SD7, SD8, SD10, and SD11 (Figures 1A and 1B); however, in the other SDs, the time accumulation was smaller (SD4, 5, 6 and 9) and greater (SD 1, 2, 3 and 12) than at $667^{\circ} \mathrm{C}$ day. For B. orellana, only SD4 and SD6 showed thermal time accumulation similar to $925{ }^{\circ} \mathrm{C}$ day. While the other SDs, mainly SD1, SD2, and SD9, had thermal time accumulation different from $925^{\circ} \mathrm{C}$ (Figure 1B), around $175^{\circ} \mathrm{C}$ day.

Estimation of the $\mathrm{LAR}_{\max }$ coefficient of WE model using a statistical approach requires a biologically meaningful calibrated (Martins and Streck, 2007; Streck et al., 2011; Uhlmann et al., 2017). The LAR ${ }_{\max }$ coefficient value was 0.1867 leaves $\mathrm{d}^{-1}$ for $C$. myrianthum and 0.1125 leaves $\mathrm{d}^{-1}$ for $B$. orellana, which represent the lowest duration of seedling phase when air temperature equals (or close to) the optimum development temperature (Ferreira et al., 2019b; Martins et al., 2014; Streck et al., 2011). In this approach, the lowest duration of the seedling phase ranged from 107 days (C. myrianthum) to 178 days $(B$. orellana). For $C$. myrianthum, this seedling phase duration is realistic under field conditions (Figure 1A) mainly in SD9, which had a greater number of days (92 days) with air temperature close to Topt $\left(18.1^{\circ} \mathrm{C}\right)$. In the other SDs, this approach showed differences ranging from +8 days (SD5) to +55 days (SD1) to reach the development plateau and finalize the seedling phase (CLN = 20 leaves), especially in the SD where air temperature surpassed Topt. The duration of the seedling phase for $B$. orellana through LAR $_{\text {max }}$ coefficient of the WE model (178 days) was similar under field conditions in SD4, SD6, and SD11 (Figure 1B); however, in the other SDs, the duration showed differences from -34 days (SD8) to +31 days (SD1).
Durations of the developmental phase are realistic under field conditions, as indicated by the number of days to end the seedling phase of both forest species (Figures $1 \mathrm{~A}$ and $1 \mathrm{~B}$ ), which correspond to the development forest species in the field when temperatures are below optimum, mainly after emergence, delaying the development.

Generally, the model evaluation showed that CLN versus predicted CLN was similar between both models (Phyl and WE) for C. myrianthum and B. orellana (Table 2). Among the SDs, the Phyl model presented RMSE values from 0.40 to 5.01 leaves, BIAS values from -0.15 to 0.36 , the Willmott index of agreement (d) was higher than 0.91 , and the c-index was greater than 0.86 , which represents an excellent performance. The WE model presented RMSE values from 0.68 to 2.90 leaves, BIAS varied from -0.22 to 0.24 , the $d$ and $c$ indexes were $\geq 0.94$, also an excellent performance. Between species, no clear trend could be detected from the RMSE, BIAS, and the $\mathrm{d}$ and c-index values (Table 2) in terms of CLN prediction, that is, the model performed better for any species in some SDs or for the same species, models did not perform as well as in the other SDs. For example, in the Phyl model, the overall c-index was 0.93 and 0.98, while in the WE model, the overall c-index was 0.96 and 0.98 , for $C$. myrianthum and $B$. orellana respectively. Streck et al. (2008) verified similar response in rice and Martins et al. (2014) in olive cultivars.

Regardless of the species and SD, both models (Phyl and WE) did not violate the normality and homogeneity assumptions (Table 3). The Bartlett test showed that variance was not significant, represented by the standard deviation (Table 3), between observed and predicted CLN by the Phyl and WE models. This response is desirable to choose the most appropriate development model (Ferreira et al., 2019b; Martins and Streck, 2007) from the biological and statistical viewpoints (Monteiro and Martins, 2019).

Furthermore, most SDs showed no statistical difference between observed and predicted CLN mean for $C$. myrianthum considering the WE model and for $B$. orellana considering the Phyl model. On the other hand, the opposite occurred when the other model and species were analyzed, that is, the Phyl model for $C$. myrianthum and the WE model for $B$. orellana showed differences between observed and predicted mean for CLN (Table 3). For both species, the predicted CLN mean by the Phyl model was higher than the observed CLN mean, except for B. orellana on SD11 and SD12. Similarly, the predicted CLN mean by Pyl model was slightly higher than the predicted CLN mean by the WE model, in most sowing dates. However, the difference average between observed and predicted CLN obtained by the Phyl model was around $17.5 \%$ (C. myrianthum) and $5.4 \%$ (B. orellana) and around $0.2 \%$ (C. myrianthum) and $12 \%$ (B. orellana) by the WE model, which validates the prediction CLN by the Phyl and WE models.

Predicted versus observed values for the main stem CLN for the independent data (pooling data for each forest species and for different SDs) are presented in Figures 3A-D. Considering the Phyl model, overall RMSE 
Table 2 - Evaluation performance to predict cumulative leaf number (CLN) considering Phyllochron (Phyl) and Wang and Engel (WE) models in two native forest species - Citharexylum myrianthum and Bixa orellana - Itajubá, Southeastern Brazil.

\begin{tabular}{|c|c|c|c|c|c|}
\hline $\begin{array}{l}\text { Sowing } \\
\text { dates }\end{array}$ & Model & $\begin{array}{l}\text { RMSE } \\
\text { (leaves) }\end{array}$ & BIAS & $\begin{array}{c}\mathrm{d} \\
\text { (dimensionless) }\end{array}$ & $\begin{array}{c}\text { c-index } \\
\text { (dimensionless) }\end{array}$ \\
\hline \multicolumn{6}{|c|}{ Citharexylum myrianthum } \\
\hline \multirow{2}{*}{ SD6 } & Phyl & 4.01 & 0.27 & 0.91 & 0.89 \\
\hline & WE & 1.36 & -0.02 & 0.98 & 0.97 \\
\hline \multirow{2}{*}{ SD7 } & Phyl & 3.76 & 0.22 & 0.91 & 0.90 \\
\hline & WE & 1.34 & -0.06 & 0.98 & 0.97 \\
\hline \multirow{2}{*}{ SD8 } & Phyl & 5.01 & 0.36 & 0.87 & 0.86 \\
\hline & WE & 1.39 & 0.05 & 0.98 & 0.97 \\
\hline \multirow{2}{*}{ SD9 } & Phyl & 1.53 & 0.08 & 0.98 & 0.98 \\
\hline & WE & 2.00 & -0.17 & 0.97 & 0.96 \\
\hline \multirow{2}{*}{ SD10 } & Phyl & 1.96 & 0.10 & 0.98 & 0.97 \\
\hline & WE & 1.80 & -0.06 & 0.98 & 0.96 \\
\hline \multirow{2}{*}{ SD11 } & Phyl & 1.52 & 0.08 & 0.98 & 0.97 \\
\hline & WE & 1.94 & 0.02 & 0.97 & 0.95 \\
\hline \multirow{2}{*}{ SD12 } & Phyl & 1.63 & 0.13 & 0.98 & 0.97 \\
\hline & WE & 2.90 & 0.24 & 0.95 & 0.93 \\
\hline \multirow{2}{*}{ Average } & Phyl & 2.77 & 0.18 & 0.94 & 0.93 \\
\hline & WE & 1.82 & 0.01 & 0.97 & 0.96 \\
\hline \multicolumn{6}{|c|}{ Bixa orellana } \\
\hline \multirow{2}{*}{ SD6 } & Phyl & 2.29 & 0.18 & 0.97 & 0.96 \\
\hline & WE & 1.11 & -0.09 & 0.99 & 0.99 \\
\hline \multirow{2}{*}{ SD7 } & Phyl & 2.08 & 0.14 & 0.97 & 0.96 \\
\hline & WE & 1.33 & -0.11 & 0.98 & 0.98 \\
\hline \multirow{2}{*}{ SD8 } & Phyl & 0.40 & 0.02 & 0.99 & 0.99 \\
\hline & WE & 2.57 & -0.22 & 0.94 & 0.94 \\
\hline \multirow{2}{*}{ SD9 } & Phyl & 1.33 & 0.08 & 0.99 & 0.98 \\
\hline & WE & 1.59 & -0.11 & 0.98 & 0.97 \\
\hline \multirow{2}{*}{ SD10 } & Phyl & 1.52 & 0.13 & 0.98 & 0.98 \\
\hline & WE & 0.68 & -0.05 & 1.00 & 0.99 \\
\hline \multirow{2}{*}{ SD11 } & Phyl & 0.80 & -0.01 & 0.99 & 0.99 \\
\hline & WE & 1.52 & -0.12 & 0.98 & 0.98 \\
\hline \multirow{2}{*}{ SD12 } & Phyl & 1.97 & -0.15 & 0.96 & 0.96 \\
\hline & WE & 1.97 & -0.14 & 0.96 & 0.96 \\
\hline \multirow{2}{*}{ Average } & Phyl & 1.48 & 0.05 & 0.98 & 0.98 \\
\hline & WE & 1.54 & -0.12 & 0.98 & 0.97 \\
\hline
\end{tabular}

The performance classification by c-index is $c>0.85=$ represents excellent performance; $0.76<\mathrm{c}<0.85=$ represents very good performance; 0.66 $<c<0.75=$ represents good performance; $0.61<c<0.65=$ represents reasonable performance; $0.51<c<0.60=$ represents poor performance; $0.41<c<0.50=$ represents very poor performance and $c \leq 0.40=$ represents extremely poor performance.

varied from 1.48 to 2.77 leaves and in the WE model, it varied from 1.54 to 1.82 leaves, both values for $B$. orellana and C. myrianthum, respectively.

For $C$. myrianthum, the WE model had a slightly better performance than the Phyl model to predict the main stem CLN, due to the scattered data closer to the 1:1 line (Figures 3A and 3B), with a slightly wider scatter above 1:1 line than below. In addition, the WE model underestimated values lower than 3 leaves in all SD, while the Phyl model underestimated values lower than 3 leaves and overestimated values higher than 15 leaves on the main stem. These results again favor the WE model, which had greater stability of predictions across the SDs.
Table 3 - Mean and standard deviation related to cumulative leaf number (CLN) observed and predicts by Phyllochron (Phyl) and Wang and Engel (WE) models in two native forest species (Citharexylum myrianthum and Bixa orellana) in each sowing date (SD), Itajubá, Southeastern Brazil.

\begin{tabular}{|c|c|c|c|c|c|c|}
\hline \multirow{2}{*}{$\begin{array}{l}\text { Sowing } \\
\text { date }\end{array}$} & \multicolumn{3}{|c|}{ Mean (leaves) } & \multicolumn{3}{|c|}{ Standard deviation ${ }^{+}$} \\
\hline & Obs & Pred Phyl & Pred WE & Obs & Pred Phyl & Pred WE \\
\hline \multicolumn{7}{|c|}{ Citharexylum myrianthum } \\
\hline$\overline{S D 6}$ & 10.16 & $12.88^{*}$ & $9.94^{\text {ns }}$ & 5.25 & $8.02^{\text {ns }}$ & $6.16^{\text {ns }}$ \\
\hline SD7 & 11.54 & $14.12^{*}$ & $10.83^{\text {ns }}$ & 5.02 & $68^{\text {ns }}$ & $5.88^{\text {ns }}$ \\
\hline SD8 & 11.18 & $15.25^{*}$ & $11.71^{\text {ns }}$ & 5.33 & $8.16^{\mathrm{ns}}$ & $6.31^{\mathrm{ns}}$ \\
\hline SD9 & 10.85 & $11.69^{*}$ & $9.03^{*}$ & 5.92 & $6.98^{\text {ns }}$ & $5.46^{\mathrm{ns}}$ \\
\hline SD10 & 13.37 & $14.74^{*}$ & $12.53^{\text {ns }}$ & 6.10 & $7.39^{\text {ns }}$ & $7.06^{\text {ns }}$ \\
\hline SD11 & 11.86 & $12.86^{\text {ns }}$ & $12.13^{\text {ns }}$ & 5.17 & $5.98^{\text {ns }}$ & $6.64^{\text {ns }}$ \\
\hline SD12 & 0.68 & $12.12^{*}$ & $13.3^{*}$ & 5.96 & $5.82^{\mathrm{ns}}$ & $6.70^{\text {ns }}$ \\
\hline \multicolumn{7}{|c|}{ Bixa orellana } \\
\hline$\overline{S D 6}$ & 10.48 & $12.4^{*}$ & $9.54^{*}$ & 5.64 & $6.81^{\text {ns }}$ & $5.22^{\mathrm{ns}}$ \\
\hline SD7 & 10.50 & $11.94^{*}$ & $9.32^{*}$ & 5.47 & $6.84^{\text {ns }}$ & $5.34^{\text {ns }}$ \\
\hline SD8 & 10.15 & $10.16^{\text {ns }}$ & $7.91^{*}$ & 5.92 & $5.98^{\text {ns }}$ & $4.68^{\mathrm{ns}}$ \\
\hline SD9 & 12.08 & $12.99^{\text {ns }}$ & $10.72^{*}$ & 5.76 & $6.59^{\text {ns }}$ & $5.78^{\text {ns }}$ \\
\hline SD10 & 11.37 & $12.38^{\text {ns }}$ & $10.78^{\text {ns }}$ & 4.96 & $5.33^{\text {ns }}$ & $4.98^{\text {ns }}$ \\
\hline SD11 & 10.81 & $10.68^{\text {ns }}$ & $9.54^{*}$ & 5.47 & $4.78^{\mathrm{ns}}$ & $4.67^{\mathrm{ns}}$ \\
\hline D12 & 10.07 & $8.57^{*}$ & $8.63^{*}$ & 5.63 & $4.36^{\mathrm{ns}}$ & $4.30^{\text {ns }}$ \\
\hline
\end{tabular}

Obs $=$ observed CLN. Pred $=$ predicted CLN. ns not significant. ${ }^{*}$ Significant at $5 \%$ by paired the t-test (compares the observed mean with each predicted mean) and by the Bartlett's test (compares the observed variance with each predicted variance). +The presented data refer to the standard deviation. The null hypothesis for paired t-test $=$ the means of the CLN observed and predicted must also be equal $(p \geq 0.05)$ and the alternative hypothesis means are unequal $(p<0.05)$. The null hypothesis for Bartlett' test is homogeneous variances $(p \geq 0.05)$ and the alternative hypothesis is $=$ heterogeneous variances $(p<0.05)$.

There was uncertainty in the choice of the best model for $B$. orellana, due to the similar performance between Phyl and WE models (Figures 3C and 3D). Although the Phyl model overestimated the CLN values in SD6 and SD7 and underestimated in SD12, data scattered were closer to 1:1 line (Figure 3C) and the overall error was slightly lower than the WE model (Figure 3D and Table 2). The Phyl model did not show any differences between observed and predicted means for CLN by the paired t-test (Table 3), except for SD6, SD7, and SD12, which presented the worst performance among the SDs. On the other hand, the WE model tended to underestimate in most SDs, except for SD9 and SD10. Although the WE model did not violate the normality and homogeneity assumptions (Table 3), it showed differences between the observed and predicted means of CLN in all SDs, except for SD10, in which the Phyl model had a slight advantage compared to the WE model to predict CLN for B. orellana.

Figures $4 \mathrm{C}$ and $4 \mathrm{D}$ present predictions and bias values with the Phyl and WE models considering SPD in days. Again, the WE model captured the SPD variation better than the Phyl model for $C$. myrianthum, while the Phyl model captured the SPD variation better than the WE model for B. orellana.

Comparing the observed to the predicted SPDs throughout the SD (Figures $4 \mathrm{~A}$ and $4 \mathrm{C}$ ), the bias (difference between predicted minus observed SPD values) for $C$. 

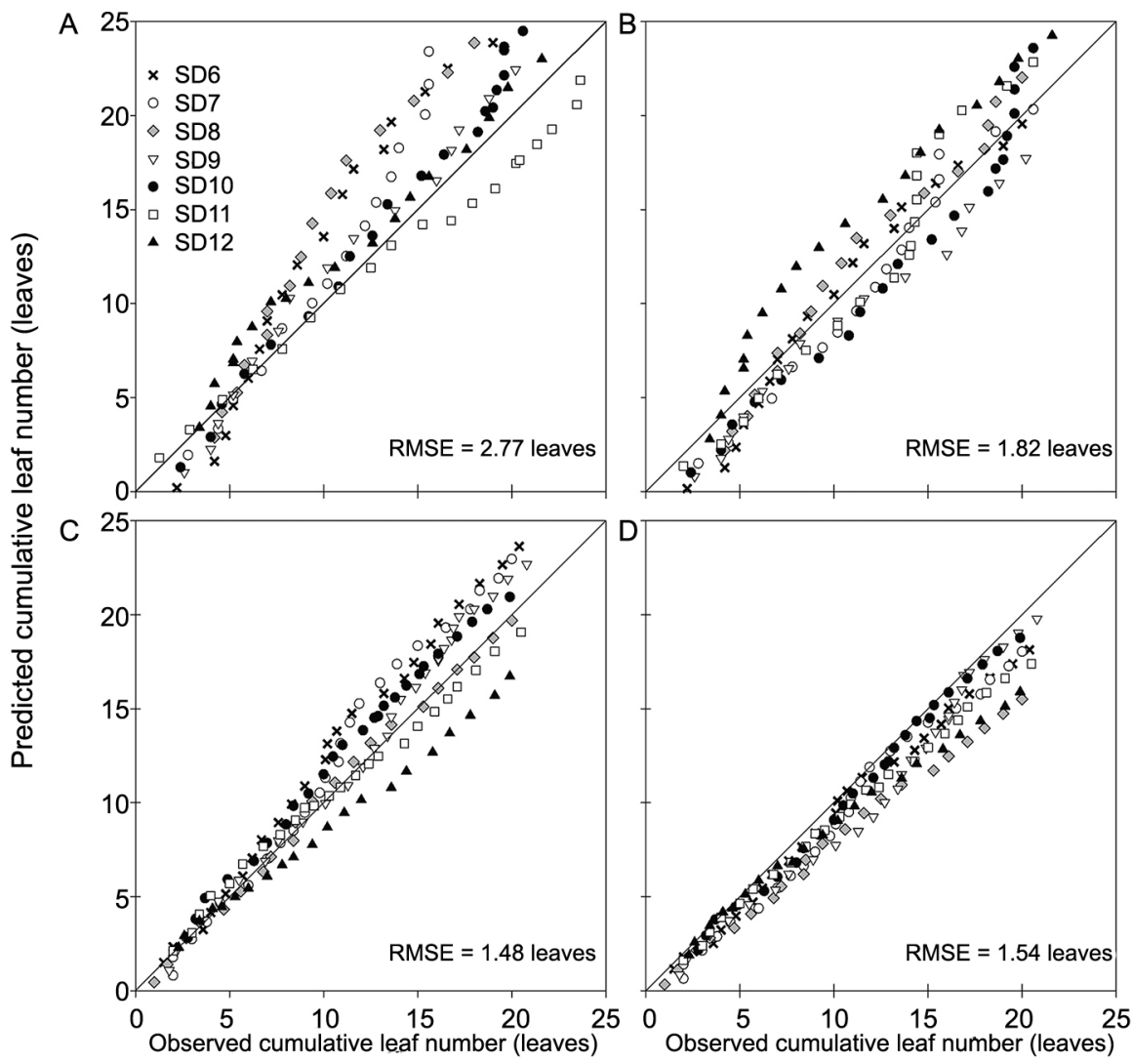

Figure 3 - Predicted versus observed cumulative leaf number (CLN) using Phyllochron model (Phyl, panels A and C) and Wang and Engel model (WE, panels B and D) for Citharexylum myrianthum (panels A, B) and Bixa orellana (panels C, D). The solid line is 1:1 line.

myrianthum varied from -7 days (SD8, 10, 11, and 12) to +7 days (SD9) with the WE model and from -37 days (SD9) to -5 days (SD12) with the Phyl model, which predicted SPD below observed SPD in all SDs (Figure 4A). The paired t-test showed no difference between the observed and predicted SPD in the WE model $(p=0.099)$, while the opposite occurred for the Phyl model $(p=0.001)$. Furthermore, the RMSE value for the WE model was 5.9 days and 26.7 days for the Phyl model, that is, the WE model captured well the SPD variation in the seven SD (Figure 4A).

For B. orellana, the Phyl model showed better SPD predictions (Figure 3B) with lower RMSE values (7.0 days) compared to the WE model (RMSE $=12.3$ days). In addition, the bias values varied from -14 days (SD6) to +5 days (SD12) with the Phyl model and from -10 days (SD8) to 19 days (SD12) with the WE model. The paired t-test showed no difference between observed and predicted SPD by the Phyl model $(p=0.079)$; however, opposite of the WE model ( $p=0.028$ ). Both predictions, CLN and $\mathrm{SPD}$, are similar considering the Phyl model for B. orellana (Figures 3B and 4B).

\section{Discussion}

In this study, both models used air temperature for the development of $C$. myrianthum and $B$. orellana species.
As air temperature drives CLN and SDP of both species (Ferreira et al., 2019a), models that predict development variables as function of air temperature should be used (Freitas et al., 2017; Martins et al., 2014; Streck et al., 2008). In this study, different SDs (Table 1) favored plants to grow under distinct meteorological conditions, mainly related to air temperature (Figures $1 \mathrm{~A}$ and $1 \mathrm{~B}$ ). This is important in the evaluation of robustness of the Phyl and WE models to predict the timing of vegetative development stage under conditions different from the calibration environments (Erpen et al., 2013; Ferreira et al., 2019b; Martins and Streck, 2007; Martins et al., 2014; Streck et al., 2011; Uhlmann et al., 2017).

The Phyl model uses a linear thermal time approach (Eq. 2) to describe the temperature effects on the development rate, while the WE model uses a nonlinear response function (Eq. 4 and 5) to describe these effects. Both models have been used to predict the LAR in several crops around the world including some regions of Brazil. For example, in Brazil, both models have been used to predict LAR in crops, such as potato (Streck et al., 2007), rice (Streck et al., 2008, 2011), sweet potato (Erpen et al., 2013), cassava (Samboranha et al., 2013), olive (Martins et al., 2014), maize (Langner et al., 2018), gladiolus (Uhlmann et al., 2017), eucalyptus seedlings (Martins and Streck, 2007), exotic forest seedlings (Monteiro et al., 2014), and 

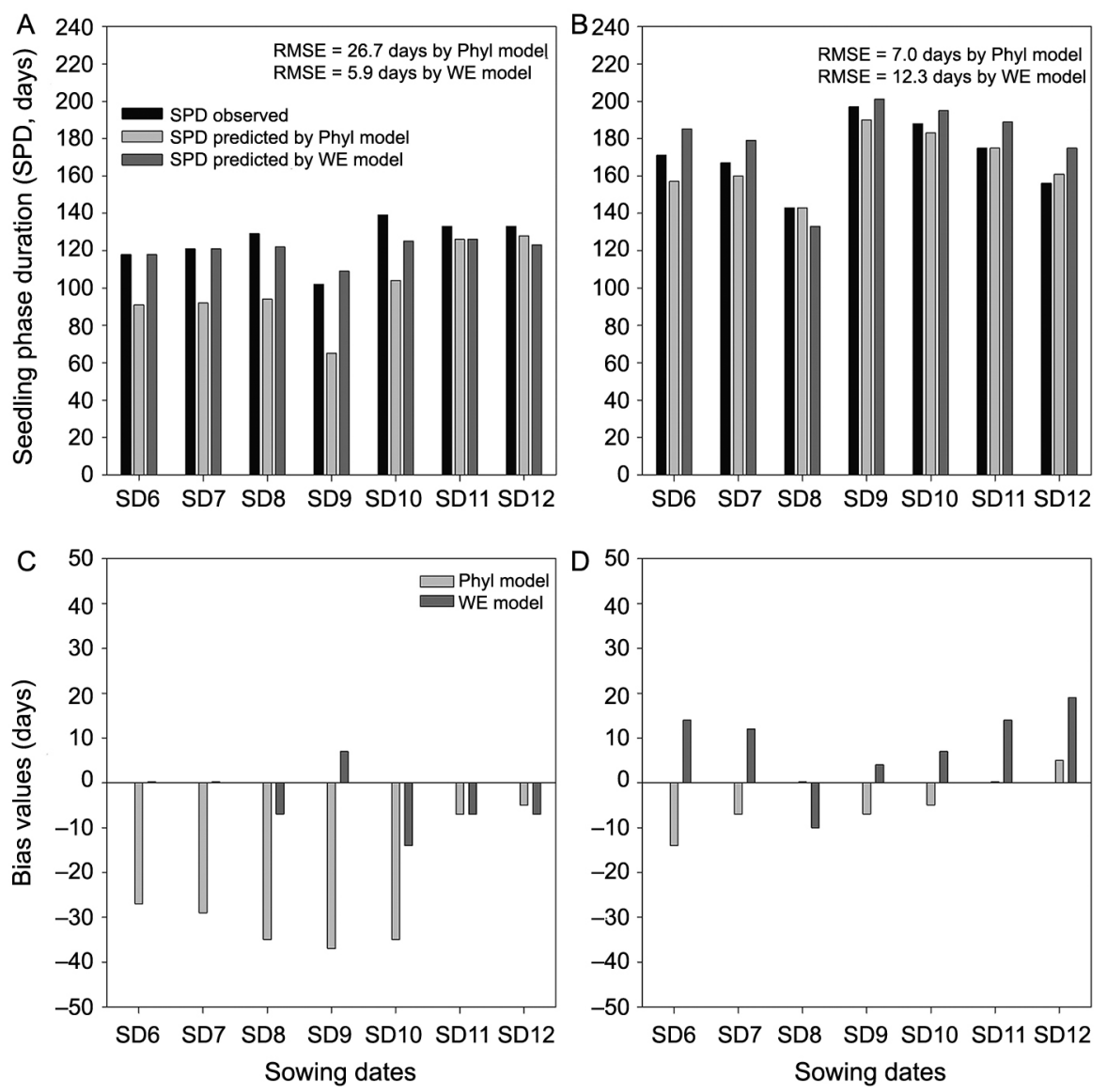

Figure 4 - Observed versus predicted seedling phase duration (SPD, days) (panels A and B) and bias values obtained by difference between predicted minus observed SPD values (panels $C$ and D) for Citharexylum myrianthum (panels $A$ and $C$ ) and Bixa orellana (panels B and D).

guava seedlings (Ferreira et al., 2019b). However, studies of this nature are scarce in native forest species. Therefore, accurate calibration of coefficients ('a' or LAR ${ }_{\max }$ )' reliable prediction of CLN and SPD, and choice of a best development model are important and necessary. All these steps produce information to be used directly or indirectly in guidance and practical applications in forest nurseries (Ferreira et al., 2019b; Martins et al., 2014; Monteiro et al., 2014) and, to verify impacts of climate changes on CLN and SPD (Becker et al., 2020; Costa and Streck, 2018; Florencio et al., 2019; Streck et al., 2011; Streck et al., 2013; Williams and Dumroese, 2004).

The WE model has been reported to be better than the Phyl model to predict developmental events in several crops, including winter wheat (Xue et al., 2004), eucalyptus seedlings (Martins and Streck, 2007), rice genotypes, red rice biotypes (Streck et al., 2011), cassava (Samboranha et al., 2013), and maize cultivars (Langner et al., 2018). However, in this study, both models predicted the dynamics of leaf development, final leaf number, and SDP time in two native forest species. The WE model predicted better the CLN and SPD for C. myrianthum species, while the Phyl model worked slightly better for $B$. orellana. The similar performance of both models, mainly as observed to CLN prediction in B. orellana, is probably because temperature remained within the range of the linear response of $B$. orellana to temperature for most days. In this case, both models performed similarly to that reported by Streck et al. (2011).

The WE model showed excellent performance among the SDs, as indicated by low RMSE and BIAS values, and by high $\mathrm{d}$ and c-index values $(\geq 0.93)$ for $C$. myrianthum (Table 2 and Figures 3B, 4A, and 4C). The RMSE value for CLN was lower than 1.82 leaves, which is lower than other crops like potato (RMSE $=2.0$ leaves) (Streck et al., 2007), sweet potato (Erpen et al., 2013), cassava (RMSE = 3.2 leaves) (Samboranha et al., 2013), olive cultivars (RMSE from 3.41 to 6.58 leaves) (Martins et al., 2014), and forest seedlings, such as Cassia fistula (RMSE $=2.4$ leaves), Parkia pendula (RMSE $=2.8$ leaves) (Monteiro et al., 2014), guava (RMSE $=2.95$ leaves) (Ferreira et al., 2019b) and Eucalyptus saligna (RMSE = 3.7 leaves) (Martins and Streck, 2007) and was similar to Eucalyptus grandis (RMSE $=2.7$ leaves) (Martins and Streck, 2007). An error lower than two leaves in $C$. myrianthum is acceptable for practical applications and represents an error inferior than seven days. Thus, this error does not affect prediction of other processes based on CLN, including the planting date (Martins et al., 2014; Langner et al., 2018; Ferreira et al., 2019b). 
The Phyl model also presented good performance to predict CLN in C. myrianthum, indicated by low values of RMSE (and BIAS) and high c-index (and d). However, it showed errors in the prediction of SPD (in days). The RMSE value with the WE model for SPD was 5.9 days and the RMSE value was 26.7 days with the Phyl model. The CLN overestimation generated by the Phyl model, especially above 15 leaves, causes underestimation of SPD (Figure 3A). The errors from the beginning of the simulations throughout the days of leaf appearance contributed to anticipating the end of seedling phase duration and, hence, the SPD predicted was lower than SPD observed.

An error below 12-15 days is accepted to predict SPD in forest species (Ferreira et al., 2019b; Martins and Streck, 2007; Monteiro et al., 2014). However, an error above 20 days is not acceptable, as it means a significant problem from a practical forest nursery perspective. For instance, if the model predicts the SPD before a target marketable day, the seedlings might not reach the marketable threshold. Therefore, it affects the price of seedlings or reduces the seedling vigor. Then, if the seedling vigor is reduced, it might reduce seedlings establishment in the field, as well as the potential forest yield (Ferreira et al., 2019a, b; Fraga et al., 2019; Martins et al., 2014; Moore and Allard, 2008).

Responses of CLN (Figures 3C and 3D) and SPD (Figures 4B and 4D) throughout the SDs for $B$. orellana showed that the Phyl model was slightly better than the WE model, even though the WE model underestimated CLN in all SDs, mainly in SD8 and SD12 (Tables 2 and 3). The SD12, installed in May 2016, showed a change between days with mild air temperatures and close to 12 ${ }^{\circ} \mathrm{C}$ (close to $\mathrm{Tb}$ ), mainly from June to Aug 2016 and days with air temperature close to Topt $\left(18.4^{\circ} \mathrm{C}\right)$, mainly from July to Sept 2016. This may have influenced sensitivity of the WE model in predicting CLN and underestimating the CLN in SD12. Nevertheless, the RMSE for CLN was similar between Phyl (RMSE $=1.48$ leaves) and WE (RMSE $=1.54)$, considered a small (and acceptable) error in development models (Ferreira et al., 2019b; Uhlmann et al., 2017). This error did not affect the good prediction of the SPD in B. orellana (Figure $4 \mathrm{~B}$ and D) with an overall error of seven days by the Phyl model and 12.3 days by the WE model.

The CLN underestimation by the WE model occurred due to the LAR decrease over time, resulting in a longer developmental cycle and overestimation of SDP in $B$. orellana in all SDs, except for SD8. Biologically, as more leaves are produced, each leaf grows longer and takes more time before emitting a new leaf, decreasing LAR over time (Martins et al., 2014; Streck et al., 2008). Nevertheless, except for SD12, the bias values between observed and predicted SPD (Figure 4D) was considered reasonable ( -10 to 14 days) and acceptable. The greatest stability of the Phyl model for B. orellana, characterized by the lowest RMSE among the SDs (Tables 2, 3 and Figures 3C, 3D, and 4D) both in CLN and SPD, compared with the WE model, indicates high robustness of this model. Therefore, the Phyl model is preferred to predict CLN and SPD for B. orellana.

The Phyl model has also been successfully used to predict CLN in the seedling phase in MSGASC315 olive cultivar (RMSE $=2.98$ leaves) (Martins et al., 2014), guava (RMSE $=1.5$ leaves) (Ferreira et al., 2019b), and tropical forest species, such as Adenanthera pavonina (L.), Cassia fistula (L.), Hymenolobium petraeum (Ducke) and Parkia pendula (Willd) (RMSE ranging from 1.41 to 8.89 leaves) (Monteiro et al., 2014). These studies reported that the Phyl model provides better results for plants that prioritize growth before developing. This may justify the slightly better performance of the Phyl model for $B$. orellana, which prioritizes the leaf growth prior to leaf development (Ferreira et al., 2019a).

This is an important step to understand the seedling development pattern in native forest species and improve the modeling of forest species. Besides, our results have practical applications and can be applied to understand the effects on CLN and SPD under climate change (Becker et al., 2020; Costa and Streck, 2018; Florencio et al., 2019; Langner et al., 2018; Streck et al., 2011; Streck et al., 2013 I to simulate the leaf appearance in forest nurseries, and to verify the ideal SD. Moreover, this approach can be used to determine the time for selling the seedlings (Ferreira et al., 2019b; Martins et al., 2014; Monteiro et al., 2014) as well as ideal moments for management nursery practices (Martins and Streck, 2007).

\section{Conclusion}

The CLN and SPD of C. myrianthum and B. orellana species are driven by air temperature. Therefore, both models used in this study predicted the dynamics of leaf development, CLN and SPD in two native forest species. The Wang and Engel model was superior for $C$. myrianthum species, while the Phyllochron model was slightly better for $B$. orellana species. The predictions of CLN and SPD for B. orellana using both models were within an RMSE lower than two leaves and seven days, which are acceptable for many practical applications in forest nurseries.

\section{Acknowledgments}

The authors thank the Minas Gerais Research Support Foundation (FAPEMIG, APQ 01258-17) for financial support, and Coordination for the Improvement of Higher Education Personnel (CAPES, process numbers 1489491 and 1827878) for granting scholarships to the $2^{\text {nd }}$ and $3^{\text {rd }}$ authors.

\section{Authors' Contributions}

Conceptualization: Martins, F.B.; Ferreira, M.C.; Florêncio, G.W.L. Data acquisition: Ferreira, M.C.; Florêncio, G.W.L. Data analysis: Martins, F.B.; Ferreira, 
M.C.; Florêncio, G.W.L. Design of methodology: Martins, F.B.; Ferreira, M.C. Writing and editing: Martins, F.B.; Ferreira, M.C.; Florêncio, G.W.L.

\section{References}

Becker, C.C.; Streck, N.A.; Uhlmann, L.O.; Cera, J.C.; Ferraz, S.E.T.; Silveira, W.B.; Balest, D.S.; Silva, L.F. 2020. Assessing climate change effects on gladiola in Southern Brazil. Scientia Agricola 78: e20180275.

Costa, D.B.; Streck, N.A. 2018. Simulating the duration of the seedling phase in eucalyptus under elevated temperature scenarios. Ciência Florestal 28: 1263-1270 (in Portuguese, with abstract in English).

Comissão de Fertilidade do Solo do Estado de Minas Gerais [CFSEMG]. 1999. Recommendations for the Use of Correctives and Fertilizers in Minas Gerais: $5^{\text {th }}$ Approach $=$ Recomendações para o Uso de Corretivos e Fertilizantes em Minas Gerais: $5^{\text {a }}$ Aproximação. CFSE-MG, Viçosa, MG, Brazil (in Portuguese).

Empresa Brasileira de Pesquisa Agropecuária [Embrapa]. Centro Nacional de Pesquisa de Florestas. 2001. Storage of Seeds of Native Forest Species $=$ Armazenamento de Sementes de Espécies Florestais Nativas. Embrapa Florestas, Brasília, DF, Brazil (in Portuguese).

Erpen, L.; Streck, N.A.; Uhlmann, L.O.; Langner, J.A.; Winck, J.E.M.; Gabriel, L.F. 2013. Estimating cardinal temperatures and modeling the vegetative development of sweet potato. Revista Brasileira de Engenharia Agrícola e Ambiental 17: 1230-1238 (in Portuguese, with abstract in English).

Ferreira, M.C.; Martins, F.B.; Florêncio, G.W.L.; Silva, J.P.G.C.; Pasin, L.A.A.P. 2019a. Cardinal temperatures and thermal requirements for the initial development of two Brazilian native species. Pesquisa Agropecuária Brasileira 54: e00525.

Ferreira, M.C.; Martins, F.B.; Florencio, G.W.L.; Pasin, L.A.A.P. 2019b. Cardinal temperatures and modeling of vegetative development in guava. Revista Brasileira de Engenharia Agrícola e Ambiental 23: 819-825.

Florencio, G.W.L.; Martins, F.B.; Ferreira, M.C.; Pereira, R.A.A. 2019. Impacts of climatic changes on the vegetative development of olive crops in Minas Gerais. Revista Brasileira de Engenharia Agrícola e Ambiental 23: 641-647.

Freitas, C.H.; Martins, F.B.; Abreu, M.C. 2017. Cardinal temperatures for the leaf development of Corymbia citriodora and Eucalyptus urophylla seedlings. Pesquisa Agropecuária Brasileira 52: 283-292.

Indústria Brasileira de Árvores [IBÁ]. 2019. Brazilian Tree Industry: Report 2019. IBÁ, São Paulo, SP, Brazil.

Langner, J.A.; Streck, N.A.; Durigon, A.; Silva, S.D.; Lago, I.; Dalmago, G.Q.; Reiniger, L.R.S.; Scheffel, L.G.; Poersch, A.H. 2018. Observed and estimated leaf appearance of landrace and improved maize cultivars. Ciência Rural 48: 1-9.

Lorenzi, H. 2014. Brazilian Trees: A Guide to the Identification and Cultivation of Brazilian Native Trees = Árvores Brasileiras: Manual de Identificação e Cultivo de Plantas Arbóreas Nativas do Brasil. Editora Plantarum, Nova Odessa, SP, Brazil (in Portuguese).

Martins, F.B.; Streck, N.A. 2007. Leaf appearance in seedlings of eucalyptus estimated by two models. Pesquisa Agropecuária Brasileira 42: 1091-1100 (in Portuguese, with abstract in English).
Martins, F.B.; Pereira, R.A.A.; Pinheiro, M.V.M.; Abreu, M.C. 2014. Leaf development in two olive cultivars estimated by two models. Revista Brasileira de Meteorologia 29: 505-514 (in Portuguese, with abstract in English).

Monteiro, E.B.; Silva, C.C.; Silva, A.C.; Souza, A.P. 2014. Estimating emission of leaves seedings Forest in different shading levels, at conditions of transition Amazon-Cerrado, Brazil. American Journal of Plant Sciences 5: 2330-2341.

Monteiro, A.F.M.; Martins, F.B. 2019. Global solar radiation models in Minas Gerais, southeastern Brazil. Advances in Meteorology 2019: ID9515430.

Moore, B.; Allard, G. 2008. Climate Change Impacts on Forest Health. Food and Agriculture Organization of the United Nations. FAO, Rome, Italy. (Working Paper FBS/34E).

Rawal, D.S.; Kasel, S.; Keatley, M.R.; Nitschke, C.R. 2015. Climatic and photoperiodic effects on flowering phenology of select eucalypts from south eastern Australia. Agricultural and Forest Meteorology 15: 231-242.

Samboranha, F.K.; Streck, N.A.; Uhlmann, L.O.; Gabriel, L.F. 2013. Mathematical modeling of leaf development in the cassava. Revista Ciência Agronômica 44: 815-824 (in Portuguese, with abstract in English).

Santos, H.G.; Jacomine, P.K.T.; Anjos, L.H.C.; Oliveira, V.A.; Lumbreras, J.F.; Coelho, M.R.; Almeida, J.A.; Cunha, T.J.F.; Oliveira, J.B. 2013. Brazilian System of Soil Classification = Sistema Brasileiro de Classificação de Solos. 3ed. Embrapa, Brasília, DF, Brazil (in Portuguese).

Snedecor, G.W.; Cochran, W.G. 1989. Statistical Methods. 8ed. Iowa State University Press, Ames, IA, USA.

Streck, N.A.; Bosco, L.C.; Lago, I. 2008. Simulating leaf appearance in rice. Agronomy Journal 100: 490-501.

Streck, N.A.; Lago, I.; Paula, F.L.M.; Bisognin, D.A.; Heldwein, A.B. 2007. Improving predictions of leaf appearance in field grown potato. Scientia Agricola 64: 12-18.

Streck, N.A.; Lago, I.; Oliveira, F.B.; Heldwein, A.B.; Avila, L.A.; Bosco, L.C. Modeling the development of cultivated rice and weedy red rice. 2011. American Society of Agricultural and Biological Engineers 54: 371-384.

Streck, N.A.; Uhlmann, L.O.; Gabriel, L.F. 2013. Leaf development of cultivated rice and weedy red rice under elevated temperature scenarios. Revista Brasileira de Engenharia Agrícola e Ambiental 17: 190-199.

Uhlmann, L.O.; Streck, N.A.; Becker, C.C.; Schwab, N.T.; Benedetti, R.P.; Charão, A.S.; Ribeiro, B.S.M.R.; Silveira, W.B.; Backes, F.A.A.L.; Alberto, C.M.; Muttoni, M.; Paula, G.M.; Tomiozzo, R.; Bosco, L.C.; Becker, D. 2017. PhenoGlad: a model for simulating development in Gladiolus. European Journal of Agronomy 82: 33-49.

Xue, Q.; Weiss, A.; Baenziger, P.S. 2004. Predicting leaf appearance in field-grown winter wheat: evaluating linear and non-linear models. Eco Modelling 175: 261-270.

Wang, E.; Engel, T. 1998. Simulation of phenological development of wheat crops. Agricultural Systems 58: 1-24.

Willians, M.I.; Dumroese, R.K. 2014. Role of climate change in reforestation and nursery practices. Western Forester 59: 11-13. 